\title{
||||||||||||||||||||||||||||||||||||||||||||||||||||||||||||||||||.
}

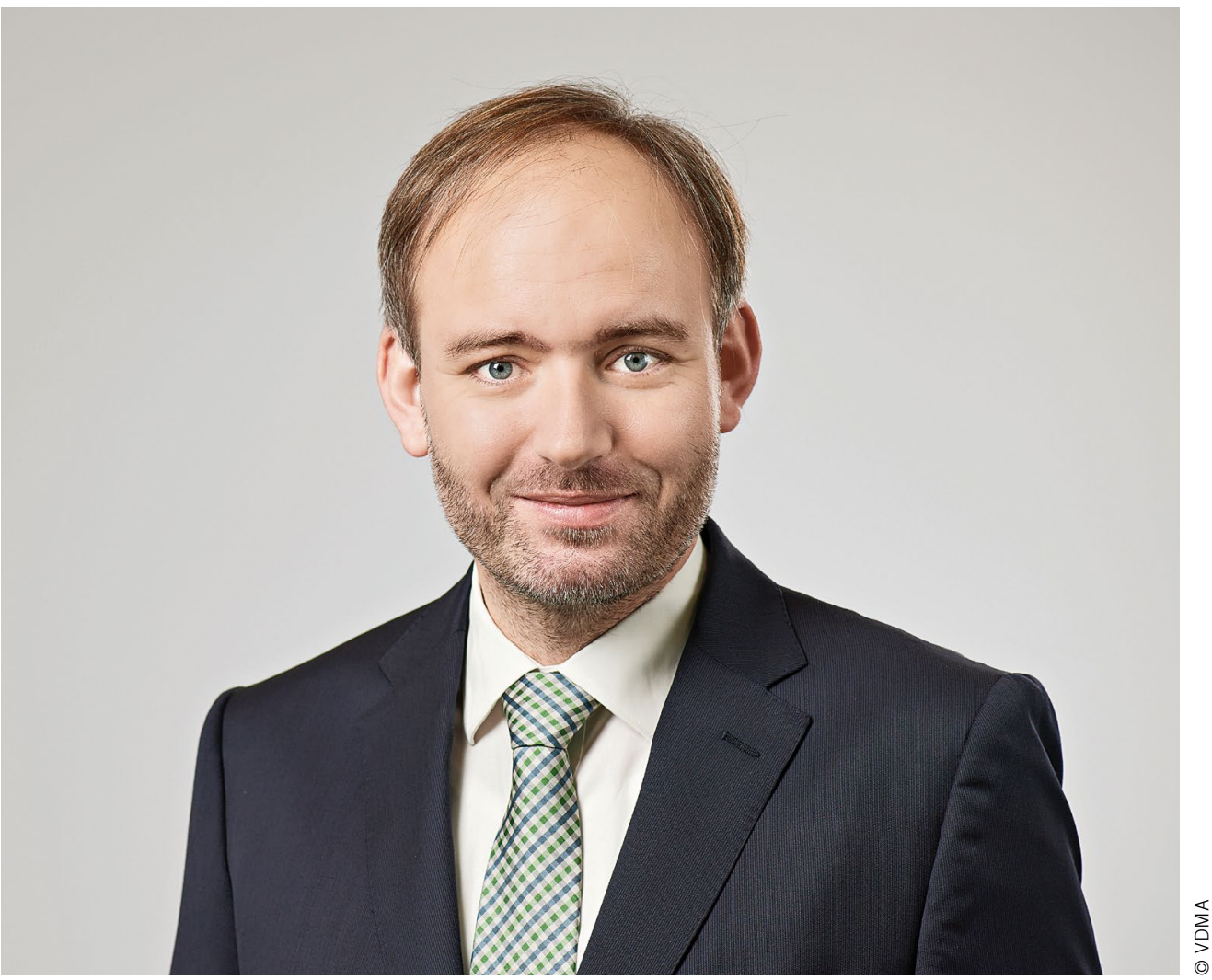

Alexander Raßmann

Projektleiter Forum \#XMotive des VDMA e. V. in Frankfurt am Main

\section{Technologievielfalt für Mobilität}

Auch während der Corona-Pandemie, die derzeit die Diskussion bestimmt, verliert die Notwendigkeit, die Klimaziele von Paris zu erfüllen, nicht an Bedeutung. Die Ziele haben höchste Priorität. Ein wichtiger Baustein hierfür, unter vielen anderen, ist die Mobilität - auf der Straße, aber auch abseits davon. Der Wandel ist bereits eingeleitet, hybride und vollelektrische Fahrzeuge werden immer mehr zum Standard.

Im Gegensatz zum Pkw - hier scheint sich der Trend zum batterieelektrischen Fahrzeug durchzusetzen - sind die Anforderungen im Bereich der Nfz und mobilen Maschinen andere und wesentlich inhomogener. Klimaneutralität wird sich für diese Fahrzeuge und Maschinen langfristig nur mit einem Mix von Technologien herstellen lassen. Es gilt, jeweils die beste Technologie für den jeweiligen Anwendungsfall zu finden. Unabhängig vom eingesetzten Energieträger muss regenerativ erzeugter Strom die Ausgangslage sein.

Die Entscheidung über Antriebssysteme bei Nfz und mobilen Maschinen ist sehr stark getrieben von den Total Cost of Ownership (TCO). Die vom VDMA gemeinsam mit FEV Consulting durchgeführte Studienserie Antrieb im Wandel gibt hierzu wichtige Erkenntnisse. Wichtiger Treiber ist die Gesetzgebung mit der Festlegung von Emissionszielen. Gerade bei schweren $\mathrm{Nfz}$ wird sich das Nutzprofil direkt auf das
Antriebssystem auswirken. Während leichte batterieelektrisch betriebene $\mathrm{Nfz}$ mit den definierten Fahrprofilen bereits heute positive TCO aufweisen, werden bei schweren Nfz mit ihrem hohen Leistungsdurchsatz eher Technologien zum Zuge kommen, die eine große Reichweite und schnelles Tanken ermöglichen. Rein elektrische Anwendungen sind aufgrund der Größe und des Gewichts der notwendigen Batterien nur eingeschränkt in diesem Bereich sinnvoll. Die Brennstoffzelle wird mit relevanten Stückzahlen in Europa schon vor 2030 beim Schwerlastverkehr eine wichtige Rolle spielen. Daher ist der Schwerlastverkehr ein wichtiger Treiber für den Aufbau einer Wasserstoffinfrastruktur. Aber auch synthetischen Kraftstoffen wird ein wichtiger Beitrag zur Klimaneutralität zugesprochen.

Bei jeder der Technologien, die zukünftig die Mobilität garantieren, wird es auf den Maschinenbau als innovativen Lösungsgeber ankommen - sei es bei hybriden und elektrischen Antrieben, im Leichtbau, bei der Batterieproduktion oder bei der Erzeugung von Kraftstoffen aus grüner Energie. Denn die Produktion ist der Schlüssel zu einer ökonomisch wie ökologisch nachhaltigen Mobilität der Zukunft. Der Maschinen- und Anlagenbau nimmt hierdurch eine führende Rolle beim Wandel der Mobilitätssysteme ein. 